\title{
ANALISIS DAN PERENCANAAN KEBUTUHAN POMPA UNTUK MEMENUHI KEBUTUHAN AIR BERSIH PDAM TIRTA TARUM KARAWANG CABANG TELUKJAMBE SEPULUH TAHUN YANG AKAN DATANG
}

\author{
Jojo Sumarjo ${ }^{1, *}$, A Arsal Arbi ${ }^{1}$, Iman Dirja ${ }^{1}$ \\ ${ }^{1}$ Jurusan Teknik Mesin, Universitas Singaperbangsa Karawang, Indonesia \\ *E-mail: jojosumarjo@gmail.com
}

Diterima: 17 Maret 2017

Direvisi: 27 April 2017

Disetujui: 5 Mei 2017

\begin{abstract}
ABSTRAK
Dengan pertambahan jumlah penduduk yang semakin pesat mengakibatkan meningkatnya kebutuhan manusia akan air bersih. Seiring meningkatnya penduduk Karawang khususnya Kecamatan Telukjambe Timur sebagai wilayah yang dianalisis yang mengakibatkan kebutuhan air meningkat pula, sementara itu sarana air bersih dari PDAM masih terbatas, maka diperlukan suatu analisis perencanaan pompa untuk memenuhi kebutuhan air bersih sehingga kebutuhan air bersih dapat terpenuhi sesuai dengan kebutuhan masyarakat. Dalam penelitian ini didapatkan kebutuhan air bersih untuk masyarakat Telukjambe Timur dan kebutuhan air bersih untuk fasilitas-fasilitas yang ada di Kecamatan Teluk Jambe Timur maka jumlah kebutuhan keseluruhan, yaitu 324,34 $\mathrm{l} / \mathrm{s}$ dan ditambah dengan faktor keamanan 64,66 l/s (20\%) maka jumlah total kebutuhan yaitu $389 \mathrm{l} / \mathrm{s}$. Sedangkan untuk kapasitas air yang dapat diproduksi PDAM Tirta Tarum Karawang Cabang Telukjambe yaitu 150 l/s. Maka dari itu PDAM Tirta Tarum Cabang Telukjambe harus melakukan penambahan debit air sebesar $239 \mathrm{l} / \mathrm{s}$. dan untuk mengatasi kekurangan debit air masyarakat Kecamatan Telukjambe Timur maka direncanakan menggunakan pompa utama sebayak 4 buah dan pompa cadangan 2 buah. Dari perhitungan yang telah dilakukan maka diperoleh kapasitas pompa yaitu sebesar $100 \mathrm{l} / \mathrm{s}$, dengan head total pompa 30,3 m, dan daya pompa $53,5 \mathrm{~kW}$.
\end{abstract}

Kata kunci: Pertumbuhan penduduk, kebutuhan air bersih, pompa

\begin{abstract}
With the population growth, this grew rapidly resulting in increasing human needs for clean water. Along with the increased population, especially the district of east Telukjambe in Karawang as a region was analyzed resulting in increased water demand. While the water supply system from PDAM is limited, it would require an analysis of the pump planning to meet the needs of clean water, so the clean water needs can be fulfilled in accordance with the needs of society. In this study, it was found that the need of clean water for society of East Telukjambe and the need for clean water facilities in the Eastern District of Telukjambe then the number of overall needs is 324,34 l/sand plus with the safety factor 64,66 l/s (20\%). So, the total amount of the clean water needs is $389 \mathrm{l} / \mathrm{s}$. While, for water capacity that can produced by PDAM Tirta Tarum subdivision in Telukjambe Karawang is $150 \mathrm{l} / \mathrm{s}$. Therefore, PDAM Tirta Tarum subdividion in Telukjambe must to make additions of water capacity in the amount of $239 \mathrm{l} / \mathrm{s}$. for overcome the shortage of water discharge of the society in East Telukjambe then the planned use of 4 pieces of the main pump and spare pump 2 pieces. From the calculations that have been conducted found that the pump capacity of $100 \mathrm{l} / \mathrm{s}$, with a total pumping head $30.3 \mathrm{~m}$, and the pump power of $53.5 \mathrm{~kW}$.
\end{abstract}

Keywords: Population growth, the need for clean water, pump 


\section{PENDAHULUAN}

Air merupakan unsur terpenting bagi kelangsungan kehidupan manusia dan makhluk hidup yang berada di bumi. Karena tampa air makhluk hidup tidak dapat bertahan hidup. (Affandy, dkk, 2014). Semua mahluk hidup membutuhkan air untuk tetap hidup dan menjalani kehidupan sehari hari. Dengan bertambahan jumlah penduduk yang semakin pesat mengakibatkan meningkatnya kebutuhan manusia akan air bersih (Hidayat, 2015 dan Nurprabowo, dkk, 2016).

Kabupaten Karawang saat ini sedang mengalami perkembangan dibidang pendidikan, sosial budaya, ekonomi dan teknologi. Pertumbuhan penduduk, sosial budaya, tingkat ekonomi, dan kemajuan teknologi di Kabupaten Karawang mengalami peningkatan tiap tahun ke tahun. Seiring meningkatnya penduduk Karawang khususnya Kecamatan Telukjambe Timur sebagai wilayah yang dianalisis yang mengakibatkan kebutuhan air bersih meningkat pula, sementara itu sarana air bersih dari PDAM masih terbatas.

Menurut, (Maindoka, dkk, 2011, dan Ramadhan, 2014), untuk mendistribusikan air bersih kepada masyarakat, diperlukan sistem jaringan distribusi yang baik, karena dengan sistem jaringan distribusi yang baik maka itu akan memperlancar pendistribusian air bersih keseluruh masyarakat atau penduduk dengan tetap memperhatikan faktor kualitas, kuantitas, dan tekanan air.

Untuk pemenuhan kebutuhan air bersih, pembangunan disektor air bersih sangatlah penting, kerena dapat meningkatkan kualitas air bersih dan juga dapat meningkatkan prasarana seperti sektor perkotaan, sektor kesehatan, sektor ekonomi dan sektor lain (Saputra, dkk, 2016, dan Setiawan, 2003).

Kuantitas air bersih yang disuplai oleh PDAM Tirta Tarum Karawang saat ini masih bisa dipenuhi dan cukup konstan karena penduduk masih banyak yang menggunakan air tanah untuk memenuhi kebutuhan sehari-hari (Sudarmono dkk, 2016, Ziana dkk, 2012, Sunarsih dkk, 2012).
Namun, pada tahun tahun selanjutnya atau pada sepuluh tahun kedepan kebutuhan air bersih akan meningkat karena diiringi jumlah penduduk yang juga ikut meningkat. Hal ini merupakan tantangan bagi pihak PDAM Tirtatarum Karawang sebagai penyuplai air bersih dalam upaya peningkatan pelayananya guna memenuhi kabutuhan air bersih masyarakat kota Karawang (Utomo dkk, 2015, Widodo dkk, 2013).

Sehingga dalam penelitian ini dilakukan analisis perencanaan pompa untuk memenuhi kebutuhan air bersih PDAM Tirta Tarum Karawang Cabang Telukjambe sepuluh tahun kedepan. Dalam penelitian ini dirumuskan permasalahannya yaitu: Bagaimanakah pengaruh pertambahan penduduk terhadap kebutuhan air bersih PDAM Tirta Tarum Karawang pada tahun 2026 menggunakan metode aritmatika, metode geometri, dan metode least square, bagaimanakah sistem distribusi air bersih pada daerah Kecamatan Telukjambe Timur sampai tahun 2026, bagaimanakah spesifikasi pompa yang sesuai akan kebutuhan air bersih dan perhitungannya.

Manfaat dari penelitian ini adalah Sebagai mutu pembelajaran bagi pihak-pihak yang membutuhkan dan juga sebagai masukan bagi PDAM Tirta Tarum Karawang dalam upaya penyediaan air bersih di Kota Karawang khususnya di Kecamatan Telukjambe Timur secara baik. Kajian dalam penelitian ini bertujuan untuk menganalisis kebutuhan air bersih PDAM Tirta Tarum Karawang sehingga pemenuhan kebutuhan air bersih pada masamasa mendatang menjadi optimal sesuai dengan kebutuhan masyarakat.

\section{METODE PENELITIAN}

Waktu dan Tempat

Penelitian ini telah dilaksanakan pada bulan Juni - Agustus 2016 di PDAM Tirta Tarum Karawang.

\section{Metode Pengambilan Data}

Metode yang kami lakukan dalam penelitian ini adalah :

A. Penentuan Lokasi Penelitian 
Lokasi penelitian dilakukan langsung di Kecamatan Telukjambe Timur dan di PDAM Tirta Tarum Karawang.

\section{B. Pengumpulan data :}

1. Data kondisi potografi, kependudukan, fasilitas Kecamatan Telukjambe Timur.

2. Data kondisi kapasitas kebutuhan air produksi, kapasitas distribusi, sumber air baku sistem distribusi PDAM Tirta Tarum Karawang.

3. Wawancara dengan pihak PDAM Tirta Tarum Karawang mengenai data-data yang diperlukan dalam penelitian.

4. Pengambilan data statistik untuk menunjang penelitian.

\section{Metode Analisa}

Metode analisa yang digunakan pada penelitian ini adalah : metode perkiraan jumlah penduduk berupa metode Aritmetika, Last-square [Usman, 2003], dan Geometri, dimana nantinya dari hasil metode ini digunakan untuk mengetahui perkiraan total debit air, dan juga penggunaan air oleh fasilitas-fasilitas umum yang ada di wilayah studi, kemudian melakukan pemilihan spesifikasi pompa berdasarkan hasil penelitian yang telah dilakukan.

\section{Prosedur Penelitian}

a. Menghitung perkiraan jumlah penduduk Kecamatan Telukjambe Timur dengan menggunakan tiga metode yaitu Aritmatika, Last-square dan Geometri. Dan dari ketiga metode ini diambil nilai yang terbesar.

b. Menghitung perkiraan kebutuhan air bersih masyarakat Kecamatan Telukjambe Timur berdasarkan proyeksi dari jumlah penduduk dan fasilitas - fasilitas di Kecamatan Telukjambe Timur.

c. Penentuan tipe pompa yang akan digunakan untuk pengembangan penyediaan air bersih.

\section{HASIL DAN PEMBAHASAN Perhitungan Penduduk}

Data dibawah ini merupakan hasil perhitungan penduduk menggunakan metode Arimmatika, Last-Square, Geometris, seperti pada Tabel 1.

Tabel 1. Perkiraan jumlah penduduk Kecamatan Telukjambe Timur 2016-2026

\begin{tabular}{c|c|c|c}
\hline \multirow{2}{*}{ Tahun } & \multicolumn{3}{|c}{ Metode } \\
\cline { 2 - 4 } & Aritmatika & Last-square & geometri \\
\hline 2016 & 149.734 jiwa & 176.387 jiwa & 173.176 jiwa \\
\hline 2017 & 153.587 jiwa & 181.217 jiwa & 178.198 jiwa \\
\hline 2018 & 157.440 jiwa & 186.047 jiwa & 183.365 jiwa \\
\hline 2019 & 161.293 jiwa & 190.887 jiwa & 188.683 jiwa \\
\hline 2020 & 165.146 jiwa & 195.707 jiwa & 194.155 jiwa \\
\hline 2021 & 168.999 jiwa & 200.537 jiwa & 199.785 jiwa \\
\hline 2022 & 172.852 jiwa & 205.367 jiwa & 205.579 jiwa \\
\hline 2023 & 176.705 jiwa & 210.197 jiwa & 211.541 jiwa \\
\hline 2024 & 180.558 jiwa & 215.027 jiwa & 217.676 jiwa \\
\hline 2025 & 184.411 jiwa & 219.857 jiwa & 223.988 jiwa \\
\hline 2026 & 188.264 jiwa & 224.687 jiwa & 230.484 jiwa \\
\hline
\end{tabular}

\section{Perhitungan Kebutuhan Air Bersih}

Jumlah kebutuhan air untuk seluruh fasilitasfasilitas $=35,34 \mathrm{l} / \mathrm{s}$

Kebutuhan air sampai tahun 2026 jumlah keseluruhan kebutuhan air bersih masyarakat dan fasilitas-fasilitas yang ada yaitu $288+$ $35,34=324,34$

Kapasitas air bersih yang dibutuhkan $\mathrm{Q}=324,34$

Faktor keamanan $=324,34 \times 20 \%$ $=64,66$

Kapasitas air yang dibutuhkan tahun (2026) Q total $=389 \mathrm{l} / \mathrm{s}$

Kapasitas air bersih saat ini (2016) $=150 \mathrm{l} / \mathrm{s}$

Jadi, penambahan debit air Qk $=239 \mathrm{l} / \mathrm{s}$

\section{Kapasitas Pompa}

Berdasarkan debit air yang akan disalurkan yaitu $=389 \mathrm{l} / \mathrm{s}$ atau $1400 \mathrm{~m}^{\wedge} 3 /$ jam atau 33.600 $\mathrm{m}^{\wedge} 3 /$ hari jadi pompa yang akan digunakan adalah 4 buah pompa utama dengan 2 pompa cadangan (Tahara dan Solarso, 1983).

Debit efektif dalam jam pengoperasian pompa,

$$
\mathrm{Q}_{\mathrm{e}}=\frac{33.600 \mathrm{~m}^{\mathrm{g}} / \text { hari }}{24}
$$




$$
\begin{aligned}
& =1400 \mathrm{~m}^{3} / \mathrm{jam} \\
& =0,389 \mathrm{~m}^{3} / \mathrm{s}
\end{aligned}
$$

Debit efektif pompa yang akan digunakan,

$$
\begin{aligned}
Q_{\text {ep }} & =\frac{\text { debit efektif }}{\text { jumlah pompa }} \\
& =\frac{0,389}{4} \\
& =0,1 \mathrm{~m}^{3} / \mathrm{s}
\end{aligned}
$$

Head Total Pompa,

$$
\mathrm{H}=\mathrm{h}_{a}+\mathrm{h}_{\mathrm{l}}+\frac{\mathrm{v}_{\mathrm{d}}{ }^{2}}{2 g}
$$

Dimana :

$\mathrm{h}_{\alpha}=$ Perbedaan tinggi antara muka air disisi luar dan disisi hisap $=-3 \mathrm{~m}$ $\mathrm{h}_{\mathrm{l}}=$ Berbagai kerugian head di pipa, katup, belok, sambungan $=33 \mathrm{~m}$ $\mathrm{V}_{d}=$ Kecepatan aliran pada pipa tekan $0.8(\mathrm{~m} / \mathrm{s})$ $\mathrm{g}=$ Percepatan gravitasi $=9,81\left(\mathrm{~m} / \mathrm{s}^{2}\right)$

$$
\begin{aligned}
H & =h_{a}+h_{1}+\frac{v_{d}^{2}}{2 g} \\
H & =-3+33+\frac{(0.8)^{2}}{2 x 9,81} \\
& =-3+33+0,032 \\
& =30,3 \mathrm{~m}
\end{aligned}
$$

Daya Motor Penggerak,

$$
\mathrm{p}_{\mathrm{m}}=\frac{\mathrm{Pp}(1+\mathrm{a})}{\eta \mathrm{t}}
$$

Dimana :

$\mathrm{p}_{\mathrm{p}}=$ Daya poros pompa $=42.378,35$

watt

$\alpha=$ Faktor yang tergantung jenis motor, motor induksi

$$
\begin{aligned}
& =0,1-0,2 \text { (lampiran }) \\
& =0,2(\text { dipilih })
\end{aligned}
$$

$\eta_{\mathrm{t}}=$ Efisensi tramsmisi (lampiran )

Maka,

$$
=0,95 \text { (kopling) }
$$

$$
\begin{aligned}
\mathrm{P}_{\mathrm{m}} & =\frac{42.378,35(1+0,2)}{0,95} \\
& =\frac{50.854,02 \mathrm{watt}}{0,95} \\
& =53,530,55 \mathrm{watt}
\end{aligned}
$$

$$
=53,5 \mathrm{~kW}
$$

\section{KESIMPULAN}

Dari hasil analisis perencanaan pompa untuk memenuhi kebutuhan air bersih PDAM Tirta Tarum Karawang Cabang Telukjambe, maka dapat ditarik kesimpulan sebagai berikut:

1. Kapasitas air yang dibutuhkan masyarakat Kecamatan Telukjambe Timur sampai tahun 2026 yaitu 389 1/s, sedangkan kapasitas produksi saat ini $150 \mathrm{l} / \mathrm{s}$, sehingga kapasitas tambahan sebesar $239 \mathrm{l} / \mathrm{s}$;

2. Head total pompa diperoleh hasil 30,3 $\mathrm{m}$;

3. Kapasitas air yg dipompa yaitu 0,1 $\mathrm{m} 3 / \mathrm{s}$ atau $100 \mathrm{l} / \mathrm{s}$;

4. Daya pompa yaitu $53,5 \mathrm{~kW}$;

5. Head total pompa yaitu $30,3 \mathrm{~m}$, kapasitas air yang di pompa sebesar 100 1/s, dan daya pompa yaitu 53,5 $\mathrm{kW}$. Karena tidak ada yang sesuai dengan spesifikasi pompa hasil perhitungan maka yang digunakan adalah spesifikasi pompa yang digunakan PDAM Tirta Tarum Karawang saat ini, yang mendekati dengan spesifikasi hasil perhitungan yang telah dilakukan, yang dipilih yaitu jenis pompa sentrifugal dengan spesifikasi sebagai berikut :

Merk pompa : Thorizima

Tipe pompa : ETA 150-500

Daya pompa : $55 \mathrm{~kW}$

Head pompa : $60 \mathrm{~m}$

Kapasitas pompa: 100 1/s

Dengan pemasangan 4 buah pompa utama secara paralel dan 2 buah pompa cadangan secara paralel.

\section{DAFTAR PUSTAKA}

Affandy, Nur A., Lubis, Z., 2014, Kebutuhan Air Bersih di Kecamatan Lamongan, Jurnal Teknika Vol 6, No.2

Dharma, I.G.B. Sila, Norken, I N., Suryadmaja, I B., 2015, Karakteristik Pola Pemakaian Dan Pelayanan Air Bersih Di Wilyah Usaha PAM PT. Tirtaartha Buanamulya, Jurnal Spektran, Vol.3, No.1

Jasin, M.I., Halim, Fuad, Kawet Lingkan, Yassin, Mohamad Oktora, 2013, Pengembangan Sistem Penyediaan Air Berih Untuk Zona Pelayanan Ipa 
Pilolodaa Kota Gorontalo, Jurnal Sipil Statik Vol. 1, No. 12

Hidayat, Arifal, 2015, Prediksi Kebutuhan Air Bersih Untuk Lima Belas Tahun Yang Akan Datang Di Kabupaten Rokan Hulu - Provinsi Riau, Jurnal Teknik Sipil, Vol. 1, No. 1

Maindoka, J dan Panjaitan, H., 2011, Analisis Pemakaian Air Bersih (PDAM) Untuk Kota Pangkep 10 Tahun Ke Depan, Skripsi Program Studi S1 Teknik Mesin Universitas Hasanuddin, Makasar

Nurprabowo, Anindito, Pharmawati, Kancitra, Affiandi, Junia, 2016, Perencanaan Sistem Instalasi Plambing Air Bersih Gedung Hotel Tebu, Jurnal Rekayasa Lingkungan, Vol. 4, No. 2

Ramadhan, A., 2014, Analisis Hidrolika Sistem Jaringan Distribusi Air Minum Di Komplek Perumahan P.T. Pusri Palembang Menggunakan Epanet 2.0, Jurnal Teknik Sipil dan Lingkungan Vol. 2, No. 2

Saputra, I.G.N.O, Suryawan, A.A.A, Suarda, M, 2016, Penyediaan Air Bersih Dengan Mengimplementasikan Katup Tekan Pompa Hydram Model Bola Di Dusun Pangkung, Jurnal Udayana Mengabdi, Vol. 15, No. 2

Setiawan, M. Ikhsan, 2003, Studi Pemenuhan Kebutuhan Air Bersih PDAM Kota Surabaya Tahun Proyeksi (2015), Neutron, Vol.3, No.1

Sudarmono, Martini, Ninik, 2015, Perencanaan Ulang Sistem Instalasi Air Bersih Kantor Otoritas Bandar Udara Wilayah III, Mekanika Jurnal Teknik Mesin, Vol. 1, No. 1

Sunarsih, Ernawati Sri, 2012, Air Bersih Untuk Masyarakat Miskin Dengan Sumur Bor, Journal of Rural and Development Vol. 3, No. 2

Tahara, H. dan Sularso, 1983, Pompa dan Kompresor, Penerbit Pradnya Paramita, Jakarta

Usman, H dan R. Akbar, R.P.S, 2003, Pengantar Statistik, Penerbit Bumi Aksara, Jakarta

Utomo, Sudiyo, Bunganaen, Wilhelmus, Tuames, Gaspar Y. K, 2015, Perencanaan Teknis Jaringan Perpipaan Air Bersih Dengan Sistem Pengaliran Pompa Di Desa Susulaku A Kecamatan
Insana Kabupaten Timor Tengah Utara, Jurnal Teknik Sipil Vol. 4, No. 1

Widodo, Basuki, Sulistyaningtyas, Annisa Dwi, 2013, Distribusi Air Bersih Pada Sistem Perpipaan Di Suatu Kawasan Perumahan, Jurnal Sains POMITS, Vol.1, No. 1

Ziana, Azmeri, Idris, Fakhrurrazi, 2012, Analisa Kinerja Jaringan Distribusi Air Bersih Di Perumnas Lingke Kecamatan Syiah Kuala Kota Banda Aceh, Jurnal Teknik Sipil, Pascasarjana Universitas Syiah Kuala, Vol. 1, No. 1 
